\title{
Finite Element Analysis of Tire Traction Using a Rubber-Ice Friction Model
}

\author{
Hyun Chul Jung, Woo Cheol Park, Kyoung Moon Jeong* \\ R\&D Center, Kumho Tire Co. Inc., Yongin, South Korea \\ Email: jhc111@kumhotire.com, *kmjeong@kumhotire.com
}

How to cite this paper: Jung, H.C., Park, W.C. and Jeong, K.M. (2018) Finite Element Analysis of Tire Traction Using a Rubber-Ice Friction Model. Open Journal of Applied Sciences, 8, 495-505. https://doi.org/10.4236/ojapps.2018.811040

Received: October 24, 2018

Accepted: November 9, 2018

Published: November 12, 2018

Copyright $\odot 2018$ by authors and Scientific Research Publishing Inc. This work is licensed under the Creative Commons Attribution International License (CC BY 4.0).

http://creativecommons.org/licenses/by/4.0/

(c) (i) Open Access

\begin{abstract}
The friction of road surface covered by snow or ice is very low and that results in reducing vehicle traction forces and potential traffic accidents. In general, to establish a master curve on a rubber-ice friction model is difficult because the ice surface, being not far removed from its melting point, reacts itself very sensitively to pressure, speed, and temperature changes. In this paper, an acceptable frictional interaction model was implemented to finite element method to rationally examine the frictional interaction behavior on ice between the tire and the road surface. The formula of friction characteristic according to temperature and sliding velocity on the ice surface was applied for tire traction analysis. Numerical results were verified by comparing the outdoor test data and it was confirmed to indicate similar correlation. It is found that the rubber-ice friction model will be useful for the improvement of the ice traction performance of tire.
\end{abstract}

\section{Keywords}

Tire, Ice Surface, Finite Element Method, Frictional Model, Temperature, Sliding Velocity

\section{Introduction}

Tire is the only component of vehicle that contacts road surface and forcetransmitting. The interaction between the road surface and the tire during vehicle driving directly affected the wear and friction, and is a main factor to ensure driving performance and stability. However, the relation between wear and friction phenomenon couldn't define simple rule due to the complexity of various mechanism. For example, the rubber wear is very high at low temperature, e.g. $\mathrm{T}=-50^{\circ} \mathrm{C}$, and it decreases by the increase of temperature until a minimum value is reached below $0^{\circ} \mathrm{C}$ [1] [2]. Conversely, in the same range of tempera- 
tures, the rubber friction initially increases with the increase of temperature and then decreases with the rise of temperature. The lower friction reduces vehicle traction forces and can be a cause of potential traffic accidents. Especially, the driving stability is not controlled because of ice and snow on the road in winter. Therefore, when developing a winter tire, it is important to predict the performance depending on operating and the environment conditions such as ice and snow road.

Many approaches of tire performance on ice surface were performed by experimental method. Shimizu et al. [3] [4] conducted similar study that the variation in longitudinal friction coefficient with crystals and texture shape of ice surface uses indoor drum type instrument. A salt and impurity also had an effect on the friction of the resulting ice surface. Skouvaklis et al. [5] implemented the experimental test that water with higher salt and impurity content exhibits lower friction coefficients with a decrease of around $15 \%$ at low temperatures. At temperatures close to $0^{\circ} \mathrm{C}$, a lesser percentage decrease was observed. Many researchers [6] [7] [8] [9] [10] observed a very significant variation in braking performance on ice, even when maintaining consistent weather conditions during testing; the variation in traction levels were observed with change in local surface texture of ice. Other ice parameters that affect the available friction levels are age of the ice track and the surface temperature. The effect of ice surface temperature on the friction coefficient was studied by Roberts [11]. Macnabb et al. [12] and Navin et al. [13] formulated a relation to predict the friction coefficient considering the vehicle speed and stopping distance based on the outdoor tests conducted on different vehicles. Friction coefficient estimation based on ambient temperature and aggregate application winter abrasive applied on roads was conducted through a model developed by Hunter [14]. Giessler et al. [15] and Bhoopalam and Sandu [16] conducted comprehensive study on the main parameters affecting the traction performance between tire and ice surface. These factors are similar to the literature described above and could be grouped into three broad areas, namely; ambient conditions and the ice conditions, tire specifications, vehicle specifications and vehicle type. Peng et al. [17] created a tire traction model of ice based on theory of thermal balance and theory of friction melting taking into effect factors. These models considered length of the contact patch, average contact pressure, thermal conductivity, thermal diffusivity and temperature of ice.

Tire traction is used to measure the ability of a tire to perform on ice surface. Traction can vary depending on a tire's tread patterns and compounds. In general, it is difficult to predict the performance considering the complex phenomena by experimental test, because the tire behavior on the icy road has many variables. Therefore, this study focused on the development of application method for predicting tire traction performance on ice surface according to the temperature and the sliding velocity change using Finite Element Analysis (FEA). The polynomial formula of friction characteristics on ice surface is applied for tire traction analysis. The 3D pattern tire model is used for FEA and the 
result of friction coefficient ( $\mu$-peak) compared with outdoor test results.

\section{Test of Ice Traction}

\subsection{Mechanism of Water Film Occurrence on Ice Surface}

Many researchers have shown that to establish mechanism on ice is difficult because its reacts itself very sensitively to pressure, speed and temperature change [15] [16] [18]. Figure 1 shows some example, the friction coefficient of different velocity as a function of the ice surface temperature at a same polymer. Near melting point of the ice the friction is low value, obviously some melting in the contact area has lubricated the road. The phenomenon which the thin water film occurs between tire and ice becomes the reason that the friction force is low. And there is no doubt that temperature and velocity could be major factors. The mechanism of the water film occurrence on ice surface road is shown in Figure 2. First, when the tire comes into contact with the ice surface and that generates heat. The heat transmitted to the ice surface and a thin water film occurs on the surface. As a result, the friction coefficient between the tire and the ice surface is reduced.

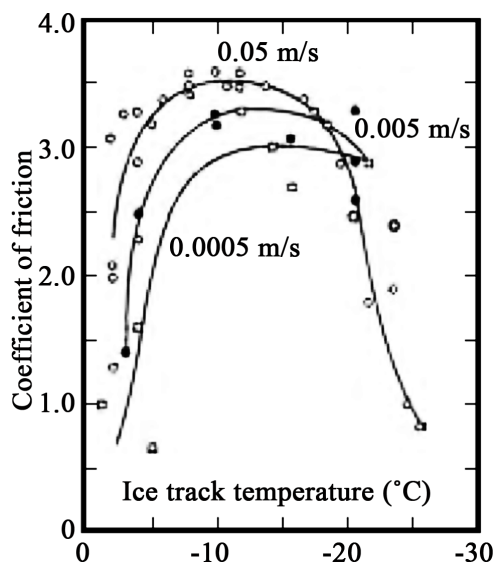

Figure 1. Friction coefficient of different velocity depending on different temperatures [18].

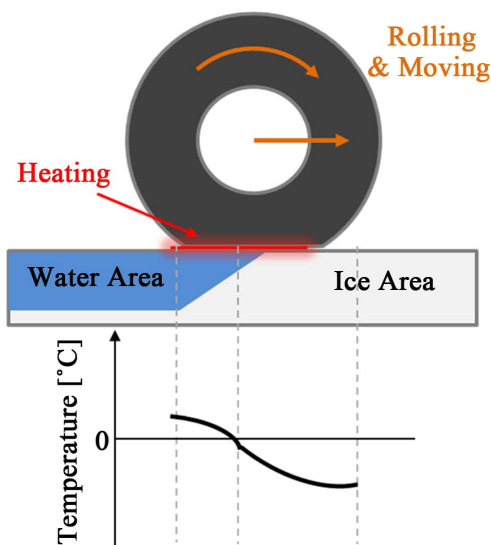

Figure 2. Mechanism of water film generation \& temperature variations on Ice surface. 


\subsection{Outdoor Test of Tire Traction on Ice}

When the most of literatures conduct the field test on ice surface, they refer international regulation such as ASTM-1572 [19], ASTM-1805 [20] and SAE-J1466 [21]. Those regulations are for evaluating the tire performance on snow and ice surface by objective testing of accelerating and braking. The test conditions such as vehicle speed, load, etc. are clearly specified, and the treaded Standard Reference Test Tire (SRTT) is used as the control tire. The control tire $\mathrm{C}$ runs every third condition, to follow sequence of Test1-Test2-C-Test3-Test4-C. The field test in this study follows the regulation in company which is based on SAE-J1466 [21]. This test method is for the tires of passenger, recreational vehicle and light truck. Test equipment can be measured velocity, checking time, acceleration and distance with Global Positioning System (GPS). The tire is mounted on the proper wheel which specified in Test Requirement \& Analysis (TR \& A) and the internal air pressure is given by regular pressure of test vehicle. The objective of ice braking distance is to check the stop distance of the vehicles on ice surface, when the vehicle fully brakes during driving at a speed of $30 \mathrm{~km} / \mathrm{h}$. Maximum tire in test procedure is 3 set; as follow C-Test1-Test2-Test3-C. In case of unstable test condition, test version can be changed 2 or 1 set. The shorter result of the stopping distance is better on braking performance. And ice acceleration test is to check the acceleration performance of the tire on the ice surface, when full throttle at the stop state. The vehicle accelerates according the test method until test speed at $30 \mathrm{~km} / \mathrm{h}$ and stops the vehicle after complete test. Test procedure is same with the stopping distance test. The shorter result of the test time is better on traction performance. All result of acceleration and stop distance takes the average more than 5 data, when standard deviation of the test data is within 0.8 . The ice surface and test environment is shown in Figure 3.
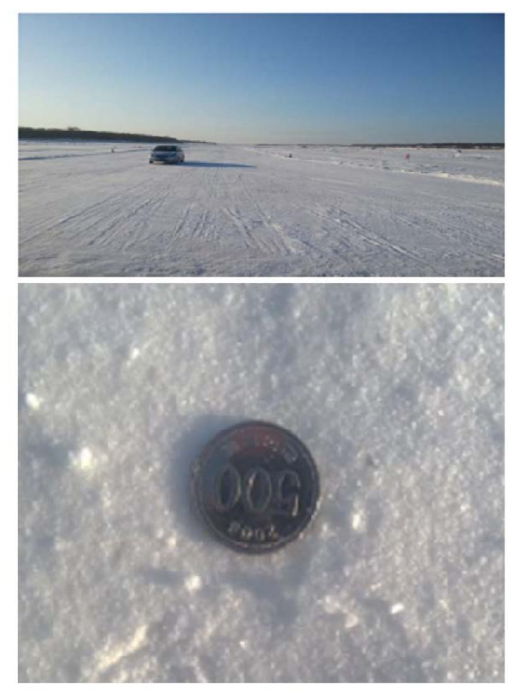

(a)
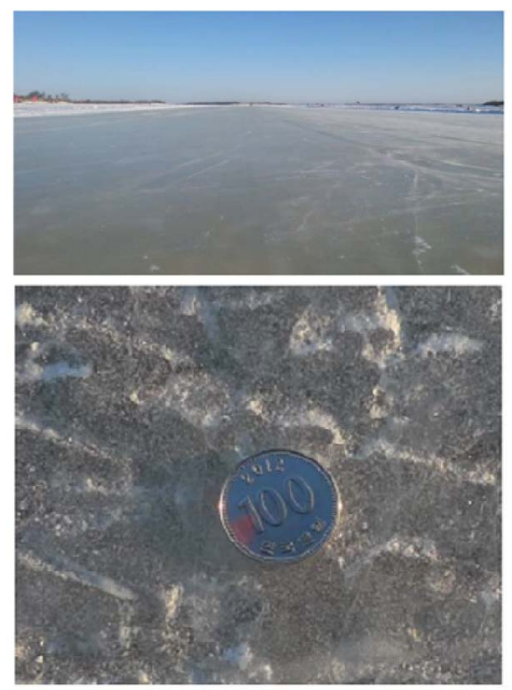

(b)

Figure 3. Snow and ice surface for acceleration and braking distance test. (a) Snow surface; (b) Ice surface. 


\section{Tire Traction Analysis}

\subsection{Finite Element Modeling of a Tire}

Different sections of a typical radial passenger car tire are shown in Figure 4. The main parts of the pneumatic tire are carcass, belt, sidewalls, beads, and tread. The carcass is made of layers of rubberized fabric that gives the strength and flexibility of tires. The steel belts are located between tread and carcass which reduces exterior impact as well as allows driving safely by keeping tread dimension wide. Covering the carcass and belts are sidewalls and tread of chemically treated rubber. The sidewalls form the outer walls of the tire. Embedded in the two inner edges of the tire are beads that hold the tire to the wheel. The underside of the tire body, inner liner, is coated with butyl rubber to keep the air from escaping. The under tread which set in among capply, belt and tread should be formed a low heat generation rubber compound to prevent the separation by bending and extension of tire. A great portion of the tire structure consists of vulcanized rubber. The rubber has a nonlinear and incompressible behavior towards loading which is independent of the strain rate. The nonlinear elastic material response is formulated by a strain energy density function accounting for large strain components. The strain energy density function is defined according to the Mooney-Rivlin material model;

$$
W\left(I_{1}, I_{2}, I_{3}\right)=A\left(I_{1}-3\right)+B\left(I_{2}-3\right)+C\left(\frac{1}{I_{3}^{2}}-1\right)^{2}+D\left(I_{3}-1\right)^{2}
$$

where the constants $A$ and $B$, and Poisson's ratio $v$ are the input parameters for the model determined from experiment. In the derivation of the constants $C$ and $D$ incompressibility is assumed as $C=0.5 A+B$ and $D=\{A(5 v-2)+B(11 v-5)\} / 2(1-2 v) . I_{i}$ is the strain invariant in terms of the principal stretches which defined as; $\delta x_{i} / \delta X_{j}=\lambda_{i j}$. Where $\delta x_{i}$ and $\delta X_{j}$ are the coordinates of the deformed and the original geometry respectively [22]. Cords inside carcass ply and belts are usually modelled by shell or membrane element. These elements are constrained to remain in the same parametric positions within the solid elements using the special feature based on the penalty method. Figure 5 shows a two dimensional finite element model of the tire,

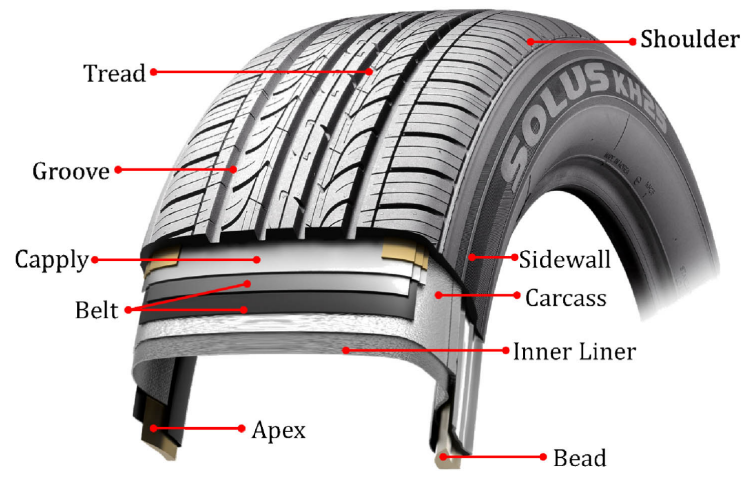

Figure 4. The structure of typical pneumatic tire. 


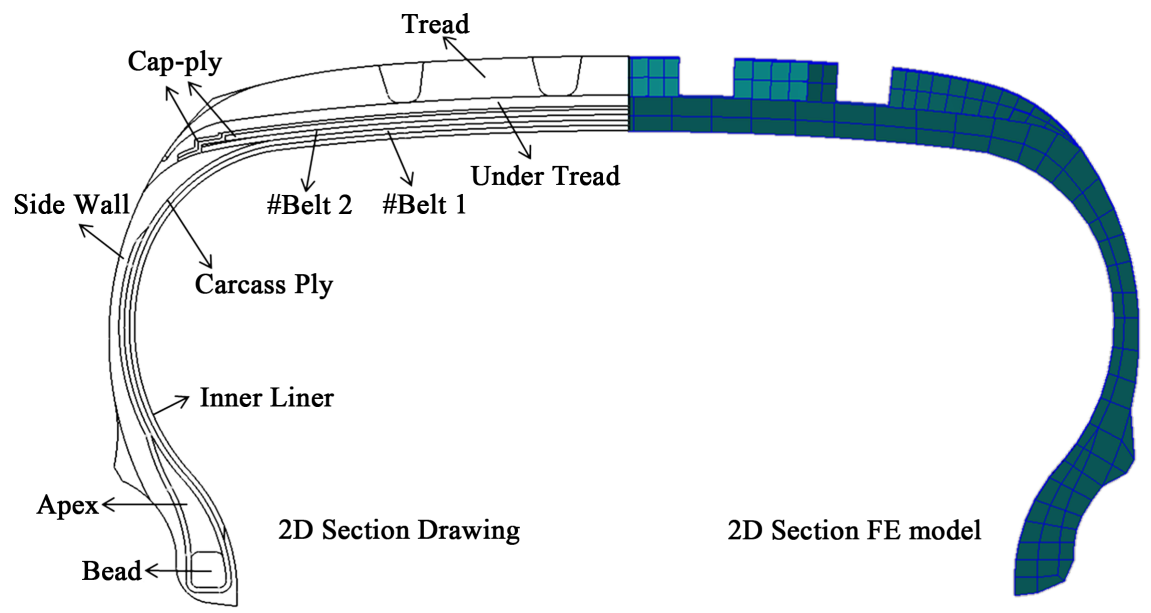

Figure 5. The 2D section drawing and finite element model of the tire.

where its components can be distinguished. Each cord layers have a different width and are situated at a different angle with respect to each other within the tire structure.

\subsection{Friction Model of Ice Surface}

Once the tire structure and material properties are modeled and implemented, the interface between the tire and the ice surface should be established. The contact of tire and road complicates the finite element model, since contact and friction problems are highly nonlinear and must reflect the characteristics of Ice. Generally, when applying friction between the tire and the road, a static friction coefficient $\mu_{s}$ and dynamic friction coefficient $\mu_{k}$ is applied which are based on a Coulomb formula [22];

$$
\mu=\mu_{k}+\left(\mu_{s}-\mu_{k}\right)^{e}
$$

where an exponential interpolation function, $e$, smooths the transition between the dynamic and static friction coefficient. In some case, the friction coefficient test value can input according to each pressure and sliding velocity. However, those methods couldn't reflect various changes of ice state which friction coefficient changes depending on temperature or sliding velocity. In this study, User Defined Subroutine (UDS) is considered to apply various changes of friction coefficient. The process of enabling UDS needs to create the desired implementation in the form of dynamic-link libraries [22]. The friction characteristics of the ice surface are derived from literature [3]. The changes of friction coefficient according to the temperature and sliding velocity are shown in Figure 6, and it is converted into a polynomial friction formula for the analysis.

$$
\begin{gathered}
\mu(t)=a t^{3}-b t^{2}-c t+d \\
\mu(v)=m v^{n}
\end{gathered}
$$

where the constants $a, b, c$ and $d$ are the input parameters for the friction 


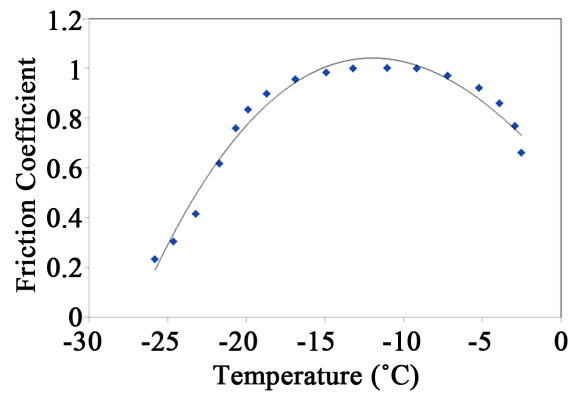

(a)

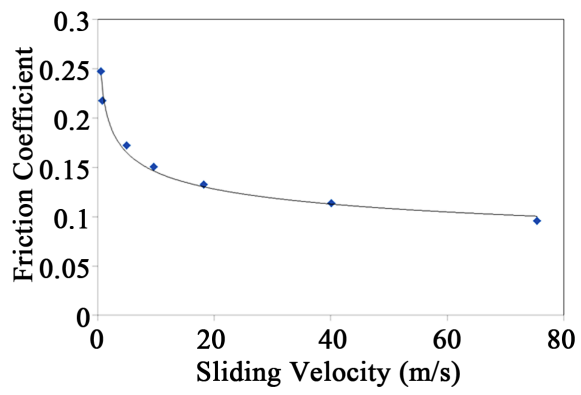

(b)

Figure 6. Rubber-ice friction model (a) Temperature; (b) Sliding velocity.

coefficient according to the temperature variation $t$. And Equation (4) is the formula of the friction coefficient according to the sliding velocity variation, $v$. And, $m$ is the input parameters for the friction coefficient determined from experiment and $n$ is an exponential interpolation function.

\subsection{Analysis Procedure}

To analyze ice traction performance $3 \mathrm{D}$ axisymmetric model is generated for tire structures every 2 degrees without tread component due to tire rotation. A 3D periodic tread pattern composed a number of uniform sectors and combine with $3 \mathrm{D}$ structure model. The road which constitutes the friction surface is modeled as flat and rigid in the finite element simulations. The specific process for analysis follows as shown in Figure 7.

- Step 1:2D \& 3D Structure and Pattern Mesh

2D meshes for tread pattern and tire structures are separately created based on $2 \mathrm{D}$ drawings. The symmetric model is used to revolve the $2 \mathrm{D}$ axisymmetric cross-section into a partial three-dimensional model. And then 3D tread models are generated from 2D meshes by the in-house program. Finally, 3D finite element model for traction performance prediction is completed by combing both $3 \mathrm{D}$ meshes.

- Step 2: Rim Mounting and Inflation

To implement tire seating phenomenon in the rim, mounting and inflation processes are carried out using a 3D axisymmetric model. The beads located on both sided move to fixed rim, and put the pressure inside the tire to fully seat it.

- Step 3: Loading and Rotating

The tire receives the proper load from vehicle and supports the road surface. The load is given in the vertical direction at the tire center. After loading, the tire rotates the road surface until it reaches a predetermined speed.

- Step 4: Result Acquisition

When an enforcement slip is applied to a rotating tire that has reached a constant speed, a force, $f_{x}$, is generated in the tire forward direction. Also, when the loading vertically from the road surface is $f_{z}$, the friction coefficient $\mu$ can be expressed as $\mu=f_{x} / f_{z}$. To compare with result of experimental test, $\mu$ peak value is obtained from result of simulation. 


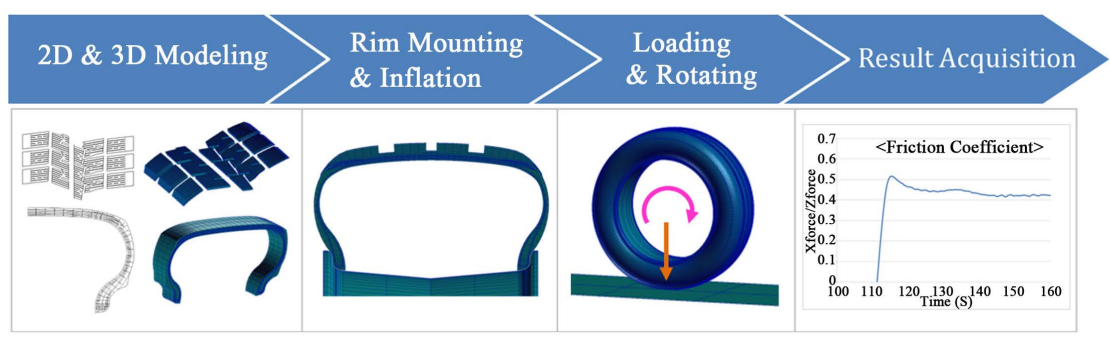

Figure 7. Specific process for finite element analysis of tire traction.

\section{Numerical Result}

\subsection{Validation of Finite Element Analysis}

In order to validate FEA-based rubber-ice friction model, the simulation of ice traction is conducted according to temperature change which is considered to be a major factor in the ice test environment. The reason for selecting temperature as the main factor is the experimental research by Roberts [10]. He studied the effect of ice surface temperature on the friction coefficient. High friction coefficient is observed on cold ice with temperature less than $-10^{\circ} \mathrm{C}$. However, at temperatures close to $0^{\circ} \mathrm{C}$, the water film drastically reduces the frictional force. In this study, the analysis temperatures are $-3^{\circ} \mathrm{C},-5^{\circ} \mathrm{C},-10^{\circ} \mathrm{C}$ and $-15^{\circ} \mathrm{C}$, and the same boundary condition is applied for each simulation such as inner pressure, load and sliding velocity. The analytical results are shown in Figure 8; the result has been confirmed similar tendency with the literature which friction coefficient has lower value at the melting temperature. In other words, the result of the analysis is similar to the polynomial friction model tendency, and it is confirmed that the UDS is applied correctly in the simulation.

\subsection{Numerical Result of Tire Traction Analysis}

In order to measure the ice traction performance of tire, the tire with a size 205/55 R16 is used in experimental test and simulation. The tire has winter pattern shape which is pattern blocks with many sipe and flexible tread compound, as shown in Figure 9. The softer compound is able to interlock with the road surface and also improving grip and handling in cold temperature. Many sipe bites into the snow, slush and ice, providing optimal grip with the winter road. Each version has different compound of pattern tread and under tread, as shown in Table 1. The experimental test is conducted near Heihe city in China. Air temperature is maintained $-9^{\circ} \mathrm{C}$ to $-11^{\circ} \mathrm{C}$ and the internal air pressure is given by 30 psi. The transient rolling simulations are performed by commercial finite element software Nastran Sol700. In order to maintain similar environment and boundary conditions, the internal pressure injected 30 psi. The initial temperature and vertical load are given $-10^{\circ} \mathrm{C}$ and $450 \mathrm{kgf}$. In the experimental test, the shorter result of the test time is better on acceleration performance, as described in Section 2.2. In the simulation, the friction coefficient is acquired as a result, and high value is better. The results of experimental test and simulation are compared as shown in Figure 10. Although there is a slight difference between 


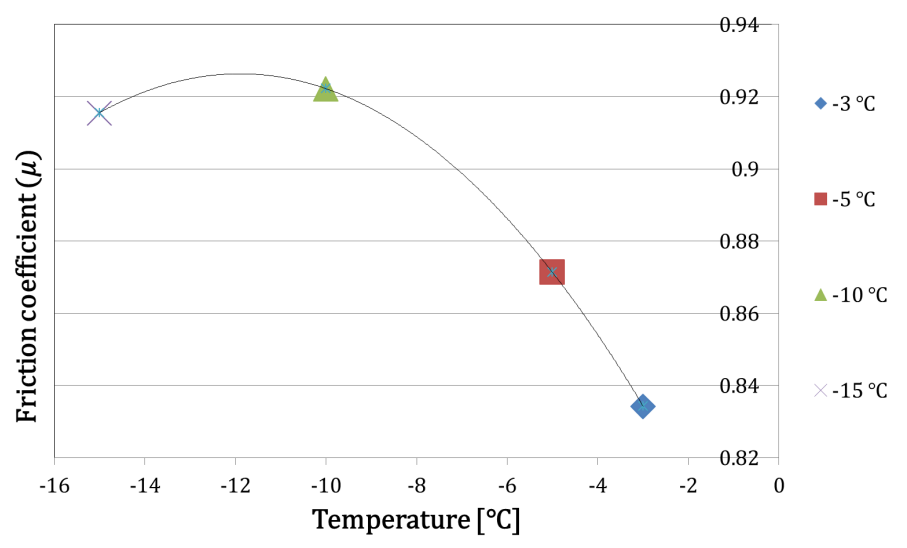

Figure 8. The result of ice traction simulation according to temperature change.
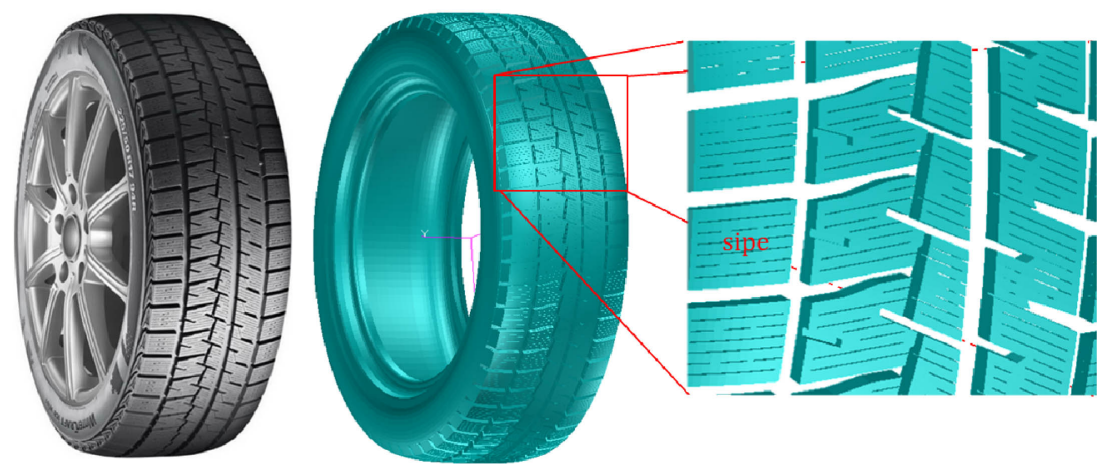

Figure 9. Tire model and winter pattern shape with many sipe.

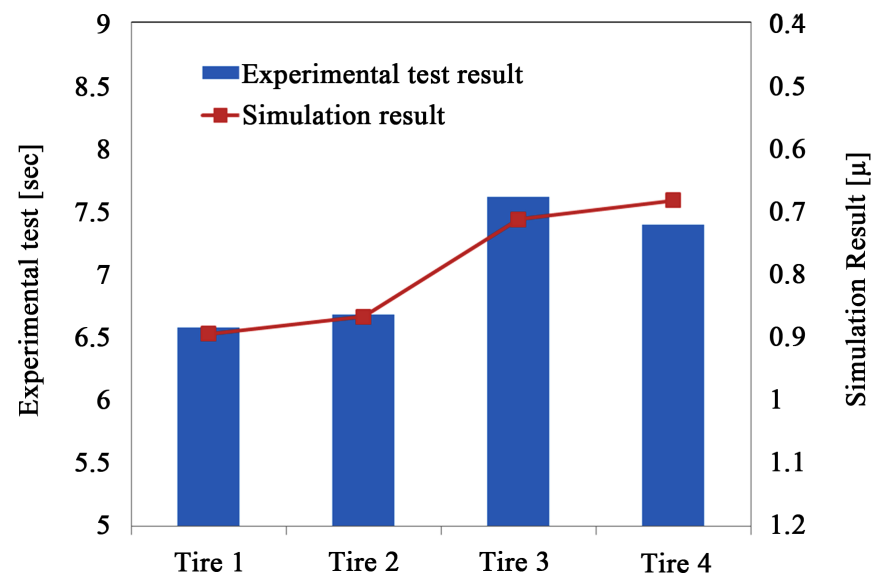

Figure 10. Tire traction performance of experimental test and simulation.

Table 1. Specific version for ice traction test and simulation.

\begin{tabular}{ccccc}
\hline \multirow{2}{*}{ Test Version } & \multicolumn{2}{c}{ Compound } & \multicolumn{2}{c}{ Result } \\
\cline { 2 - 5 } & Pattern Tread & Under Tread & Experimental Test $[\mathrm{sec}]$ & Simulation $[\mu]$ \\
\hline Tire 1 & MAT A & MAT C & 6.58 & 0.894 \\
Tire 2 & MAT A & MAT D & 6.68 & 0.867 \\
Tire 3 & MAT B & MAT C & 7.61 & 0.712 \\
Tire 4 & MAT B & MAT D & 7.39 & 0.683 \\
\hline
\end{tabular}


experimental test and simulation due to explicit analysis, the results show that the effect of pattern tread compound is much bigger. Tire 1 and Tire 2 with MAT A as a pattern tread compound have better performance and Tire 1 is the best version for both of the experiment and simulation.

\section{Conclusion}

A numerical method for predicting the tire traction on ice surface has been introduced in this paper to reduce time and cost that is required for outdoor test of a tire at the pattern design stage. A rubber-ice friction model described in this paper is derived based on the laboratory testing [17]. The friction characteristics of ice surface are applied to the finite element analysis with temperature and velocity changes. The simulation of tire traction performance on ice is implemented by transient dynamic rolling analysis of the 3D patterned tire model. And also outdoor test is conducted to verify the numerical results. It is found that the tread compound is more influential than under tread compound and the both of experiment and simulation results have shown similar tendency. Therefore, the tire traction performance on ice surface could be predicted by the friction characteristics according to temperature and sliding velocity changes. In order to obtain more accurate analysis results, it is expected that the development of ice surface simulates the phenomenon of heat and water film generation due to contact between rubber and ice surface road in the future.

\section{Acknowledgements}

The present study was supported by the Center for Environmentally Friendly Vehicles (CEFV) under the project "Development of the global top eco-friendly tire for reduction of tire wear particles and carbon dioxide" through the Ministry of Environment (ME, Republic of Korea).

\section{Conflicts of Interest}

The authors declare no conflicts of interest regarding the publication of this paper.

\section{References}

[1] Schallamach, A. (1968) Recent Advances in Knowledge of Rubber Friction and Tire Wear. Rubber Chemistry and Technology, 41, 209-244. https://doi.org/10.5254/1.3539171

[2] Grosch, K. (2004) Correlation between Road Wear of Tires and Computer Road Wear Simulation Using Laboratory Abrasion Data. Rubber Chemistry and Technology, 77, 791-814. https://doi.org/10.5254/1.3547852

[3] Shimizu, K. and Ikeya, C. (1989) Indoor Test of Ice and Snow Tires on Iced DrumDevelopment of Tester and Characteristics of Coated Ice for Test. SAE Technical Paper 890004, 47-52. https://doi.org/10.4271/890004

[4] Shimizu, K., Nihei, M. and Doremieux, F. (1992) Effect of Texture of Iced Road Surface on Characteristics of Tires. SAE Technical Paper 920018, 116-119. 
[5] Skouvaklis, G., Blackford, J. and Koutsos, V. (2012) Friction of Rubber on Ice: A New Machine, Influence of Rubber Properties and Sliding Parameters. Tribology International, 49, 44-52. https://doi.org/10.1016/j.triboint.2011.12.015

[6] Eddie, R. (1994) Ice, ABS and Temperature. Journal of Passenger Cars, 103, 917-922. https://doi.org/10.4271/940724

[7] Shoop, S.A. (1995) Vehicle Bearing Capacity of Frozen Ground over a Soft Substrate. Canadian Geotechnical Journal, 32, 552-556. https://doi.org/10.1139/t95-057

[8] Parker, M.W., Shoop, S.A. and Coutermarsh, B.A. (2009) Verification and Validation of a Winter Driving Simulator. Journal of Terramechanics, 46, 127-139. https://doi.org/10.1016/j.jterra.2009.05.002

[9] Shoop, S.A. and Coutermarsh, B.A. (2009) Tire Slip-Angle Force Measurements on Winter Surfaces. Journal of Terramechanics, 46, 157-163. https://doi.org/10.1016/j.jterra.2008.08.002

[10] Zhang, Y.C., Gao, J.W. and Li, Q. (2018) Experimental Study on Friction Coefficients between Tiretread Rubber and Ice. AIP Advances, 8, 1-9.

[11] Roberts, A.D. (1981) Rubber-Ice Adhesion and Friction. The Journal of Adhesion, 13, 77-86. https://doi.org/10.1080/00218468108073176

[12] Macnabb, M., Baerg, R., Sanderson, S. and Chafe, B. (1996) Tire/Ice Friction Values. SAE Technical Paper 960959, 3-11.

[13] Navin, F., Macnabb, M. and Nicolletti, C. (1996) Vehicle Traction Experiments on Snow and Ice. SAE Transactions, 105, 702-713.

[14] Hunter, J. (1993) Reconstructing Collisions Involving Ice and Slippery Surfaces. SAE Transactions, 102, 1425-1436. https://doi.org/10.4271/930896

[15] Giessler, M., Gauterin, F., Wiese, K. and Wies, B. (2010) Influences of Friction Heat on Tire Traction on Ice and Snow. Tire Science and Technology, 38, 4-23. https://doi.org/10.2346/1.3298679

[16] Bhoopalam, A.K. and Sandu, C. (2015) Experimental Investigation of Pneumatic Tire Performance on Ice: Part 1 Indoor Study, Part 2 Outdoor Study. Journal of Terramechanics, 60, 43-62.

[17] Peng, X.D., Guo, K.H. and Xie, Y.B. (2003) Advances in Study on Traction Behavior of Automotive Tire on Icy and Snowy Highways. Tribology, 23, 451-456.

[18] Grosch, K.A. (2007) Rubber Friction and Its Relation to Tire Traction. Rubber and Chemistry and Technology, 80, 379-411. https://doi.org/10.5254/1.3548172

[19] ASTM-1572 (2005) Test Methods for Tire Performance Testing on Snow and Ice Surfaces.

[20] ASTM-1805 (2000) Test Method for Single Wheel Driving Traction in a Straight Line on Snow and Ice-Covered Surfaces.

[21] SAE-J1466 (2001) Passenger Car and Light Truck Tire Dynamic Driving Traction in Snow.

[22] MSC Nastran (2016) Explicit Nonlinear (Sol700) User's Guide. 